\title{
Surgical History's missing figures - a brief discussion on the under-representation of female neurosurgeons in the archives of history
}

\author{
Manal Ahmad ${ }^{1 *}$, Basma Ahmad ${ }^{2}$ \\ ${ }^{1}$ Department of Neurosurgery, Royal Victoria Hospital, Belfast, Ireland; Belfast Health and Social Care Trust, Ireland \\ ${ }^{2}$ Royal College of Surgeons Ireland - Medical University of Bahrain, Ireland
}

${ }^{*}$ Corresponding author: Manal Ahmad, Department of Neurosurgery, Royal Victoria Hospital, Belfast, Ireland; Belfast Health and Social Care Trust, Ireland; Email: manalahmad.ma@gmail.com

Received: March 25, 2019; Accepted: March 31, 2019; Published: April 20, 2019;

\section{Original Article}

Neurosurgery is a bridge between many worlds - the ancient origins of its procedures tie into the cutting edge technological advances that drive the field forward today. It is a balance between the intricate skills required in microscopic surgery to the more robust spinal surgical procedures. Women comprise over half of the annual medical student population yet in surgical fields and especially in Neurosurgery, this filters down to between $10-12 \%[1,2]$ with progression to leadership roles in this area even more so rare - this is a gap which still needs to be bridged. In the current age wave of political correctness and openly acknowledging the generational gender inequality that has seeped into the very fabric of our economic and social conduct, one can't help but wonder if the same could be said for the current health care system. As we slowly see a shift of women opting for once male dominated surgical departments, we should also endeavour to reflect this in our history of surgery and medicine that is often a source of inspiration for young minds. According to the Health and Social Care Information Centre 2013/14, female surgeons comprise of almost a third of all surgical trainees, however of all of the current surgical consultants in England, only 11\% are women [3]. We must shed a light on the surgical specialties that may often be under-populated in the medical census such as neurosurgery and appreciate that while there is a progressive increase of women in surgery, it may be unbalanced and often skewed towards certain principles than others.

Perusing through the pages of any medical book for students or residents of examples not unlike those of Harvey Cushing and Walter Dandy who were no doubt, pioneers in their field. However, there is a deafening silence when it comes to discussing leading female neurosurgeons. Although to ate there are 12 women who have won the Nobel prize in physiology or medicine and 8 in chemistry and physics, we have been only taught about Marie Curie, a figure who comes to the minds of most students when asked. In Neurosurgery, we have heard of Dr Diana Beck and Dr.Sofia Ionescu, the first reported female neurosurgeons in the world in 1947 and 1945 respectively but this remains a niche area of interest which is slowly but surely gaining momentum.
A 2014 paper by Hariz et al discusses the contributions by female neurosurgeons and neurophysiologists in advancing stereotactic basal ganglia surgery including Dr.Gunvor Kullberg who contributed in early CT imaging and functional imaging of stereotactic lesions in Parkinson's Disease and psychiatric patients and Dr.Hilda Molina, paving the way for MER guided transplant surgery in Parkinson's patients. Furthermore, Dr. Veerle Vandewalle is a pioneer for deep brain stimulation for patients with Tourette's Syndrome [4]. It is worth recognising that it was not until 2007 that the first woman to be voted into the AANS was in 2007 and first female President of the AANS, Dr Shelly Timmons, was not elected till April 2018 [5-7].

This historical underrepresentation can be attributed to a myriad of factors. Female neurosurgeons reported being influenced by factors such as lack of mentorship and leadership training as well as negotiating skills which seem to be recurring themes $[2,8]$. This is reflected by the disparity between residency completion with $76 \%$ of women versus $87.2 \%$ of men completing residency and only $63 \%$ of women becoming board certified in contrast to $81.3 \%$ of male neurosurgery residents [9]. Is it then perhaps this skewed representation at the higher levels that influences what we know and learn from the history books and archives?

Dr Somma, an Italian neurosurgeon discussed this in depth, citing that female residents experiencing the impostor syndrome, a persistent fear of impropriety, by tending to point out their own fears and express their flaws, underrating themselves. Is it this reflection that often does not encourage female neurosurgeons to seek equal historical representation as well?[5]. Conversely, in India, there is an increasing number of highly-educated women entering the medical workplace annually yet multiple cultural factors discourage women from opting for highly competitive and male-dominated fields such as neurosurgery. Women are still very much "stereotyped in Indian society [who have] better acceptance of female doctors as gynecologists" [11]. This ostracized approach of not accepting that women can treat others beyond their own is very much an out dated approach in modern cultures yet seems to persist in a large percentage of the population. In contrast, we have seen a shift in Japanese Neurosurgical departments 
who maintain almost $29 \%$ of their residents as being female many of whom "were satisfied with their job status" when discussed [11].

In the last few number of years, we have seen an increasing number of articles and reports of pioneer female neurosurgeons in their respective countries - this is a refreshing and welcome change noted and lauded by many. It has also provided a reason to discuss this more openly and encourage diversity among all surgical specialties. It is safe to say that we are on the right track. Whilst there is still much for us to achieve before we reach an equilibrium, it may be time to change some of our old adages. Ultimately, the onus falls on us to represent history in the diverse and equal manner to future generations who will inevitably seek inspiration in their journey through this diverse, interesting and ever evolving field.

\section{Abbreviations}

AANS: American Association of Neurological Surgeons

WIN: Women in Neurosurgery (society)

\section{References}

1. Bean J. (2008) Women in neurosurgery. J Neurosurg. 109(3): 377.oi: 10.3171/ JNS/2008/109/9/0377.

2. Steklacova A, Bradac O, de Lacy P, Benes V. (2017) E-WIN Project 2016: Evaluating the Current Gender Situation in Neurosurgery Across Europe-An Interactive, Multiple-Level Survey. World Neurosurg. 104: 48-60. doi: 10.1016/j. wneu.2017.04.094.[Crossref]

3. The Royal College of Surgeons England. Surgery and The NHS in Numbers; https: //www.rcseng.ac.uk/news-and-events/media-centre/mediabackground-briefingsand-statistics/surgery-and-the-nhs-in-numbers/

4. Hariz GM et al; Women pioneers in basal ganglia surgery; Parkinsonism \& Related Disorders, Volume 20, Issue 2, 137 - 141. [Crossref]

5. Somma T, Cappabianca P; (2019) Women in Neurosurgery: A Young Italian Neurosurgeon's Perspective. World Neurosurgery, 15-18. [Crossref]

6. Gilkes CE. (2008) An account of the life and achievements of Miss Diana Beck, neurosurgeon (1902-1956). Neurosurgery. 62(3): 738-42. [Crossref]

7. Ciurea AV, Moisa HA, Mohan D. (2013) Sofia Ionescu, the first woman neurosurgeon in the world. World Neurosurg. 80(5): 650-3. [Crossref]

8. Abosch A, Rutka JT. (2018) Women in neurosurgery: inequality redux. J Neurosurg. 129(2): 277-81. [Crossref]

9. Lynch G, Nieto K, Puthenveettil S, Reyes M, Jureller M, Huang JH, et al. (2015) Attrition rates in neurosurgery residency: analysis of 1361 consecutive residents matched from 1990 to 1999. J Neurosurg. 122(2): 240-9. [Crossref]

10. Spetzler RF. (2011) Progress of women in neurosurgery. Asian J Neurosurg. 6(1): 6-12. [Crossref]

11. Yagnick NS, Tripathi M; (2018) From Conversation to Transformation: Mens' Perspective on Strange Nuances of Neurosurgical Practice for Women in India. World Neurosurgery 117(11). [Crossref]

12. Fujimaki T, Shibui S, Kato Y, Matsumura A, Yamasaki M, Date I et al. (2016) Working Conditions and Lifestyle of Female Surgeons Affiliated to the Japan Neurosurgical Society: Findings of Individual and Institutional Surveys.. Neurol Med Chir (Tokyo). 56(11): 15-18. [Crossref]

\section{Citation:}

Manal Ahmad, Basma Ahmad (2019) Surgical History's missing figures - a brief discussion on the under-representation of female neurosurgeons in the archives of history. $J$ Clin Res Med Volume 2(1): 1-2. 